\title{
Investigation of Flow Behavior around Corotating Blades in a Double-Spindle Lawn Mower Deck
}

\author{
W. Chon \\ Department of Mechanical Engineering, University of Wisconsin-Milwaukee, P.O. Box 784, Milwaukee, WI 53201, USA \\ Email: wchon2000@yahoo.com
}

R. S. Amano

Department of Mechanical Engineering, University of Wisconsin-Milwaukee, P.O. Box 784, Milwaukee, WI 53201, USA Email:amano@uwm.edu

Received 4 September 2003

\begin{abstract}
When the airflow patterns inside a lawn mower deck are understood, the deck can be redesigned to be efficient and have an increased cutting ability. To learn more, a combination of computational and experimental studies was performed to investigate the effects of blade and housing designs on a flow pattern inside a $1.1 \mathrm{~m}$ wide corotating double-spindle lawn mower deck with side discharge. For the experimental portion of the study, air velocities inside the deck were measured using a laser Doppler velocimetry (LDV) system. A high-speed video camera was used to observe the flow pattern. Furthermore, noise levels were measured using a sound level meter. For the computational fluid dynamics (CFD) work, several arbitrary radial sections of a two-dimensional blade were selected to study flow computations. A three-dimensional, full deck model was also developed for realistic flow analysis. The computational results were then compared with the experimental results.
\end{abstract}

Keywords and phrases: experimental investigation, computational fluid dynamics, laser Doppler velocimetry, lawn mower, rotating blades.

\section{INTRODUCTION}

Researching the aerodynamics of a rotating blade is important for improving the design of numerous rotating machines, such as hover crafts, VTOL, lawn mowers, fans, blowers, and snow blowers. To date, most blade designs have been the result of experience through numerous trials. However, such trials and error procedures are time-consuming and require high production costs. Therefore, the flow patterns near a rotating blade are not well understood, and it is difficult to explain the complete fluid dynamic characteristics that occur in lawn mowers during operation.

Clearly, there is a need for investigations to help mower designers optimize the configurations of blades and decks, and improve product performance. The objectives of this study are to experimentally and computationally observe the effects different blade configurations have on the flows generated in a mower housing, and to develop a flow simulation that can predict improved designs. This database could be utilized for aerodynamic studies in turbomachinery and

This is an open access article distributed under the Creative Commons Attribution License, which permits unrestricted use, distribution, and reproduction in any medium, provided the original work is properly cited. other aerodynamic applications. To achieve these goals, measurements of the velocity field around rotating blades in a housing and computational simulations of blades and the mower deck were performed. Additionally, high-speed video footage was taken to gain further insight into the flow conditions within the housing. The model we used is a type of double-spindle, corotating discharging deck, which is one of the most common mowers on the market.

The two-phase flow inside a mower hosing is a gas-solid particle system (air-grass clippings), similar to cyclones, separators, dust collectors, and snowdrifts. The grass clippings circulate with air inside the mower housing after being cut. This flow pattern inside a mulching mower deck was carefully investigated since clipping size and motion are important factors for lawn mower performance. The blades tested are designed in such a way that the angle of attack varies along the radial direction. This design creates complicated flow patterns inside the deck.

\section{EXPERIMENTAL SETUP}

The facilities used for this experiment consisted of a deck model, a running motor, a grass-feeding system, a pulley and v-belt system, a power supply, an automatic cutoff switch 


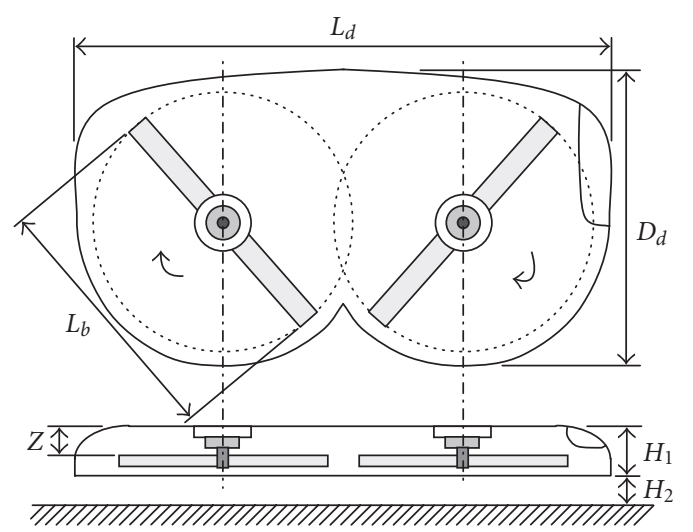

FIGURE 1: Schematic diagram of discharge-type mower deck Model

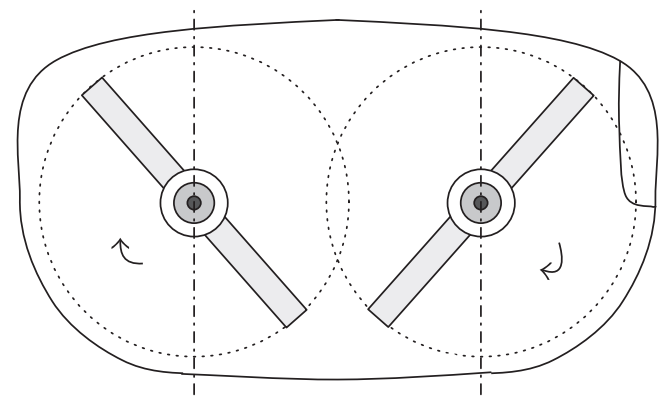

FIgure 2: Schematic diagram of mower deck Model II.

system, a velocity measuring system (LDV), an LDV traversing system, three particle generators, and a data acquisition system.

We observed the flow pattern inside the housing with a TSI laser Doppler velocimetry (LDV) system. Data were collected at several different azimuth and axial sections of the deck. In conjunction with the velocity measurements, a high-speed video camera was used to observe the flow pattern caused by the blades' rotation. A sound level meter was then used to measure the noise level generated by the running mower.

Two different housing designs of discharge-type mower deck were tested in this study. Model I has a protrusion located at the rear side of the housing. Model II was modified from Model I by removing the protrusion part. The same blade was used in both.

Figure 1 shows a schematic diagram of Model I and Figure 2 shows the redesigned housing of Model II. These models are clockwise, corotating double-blade mower decks with side discharge and a double-housing design. Their dimensions are listed in Table $1 . V_{\max }, \omega$, and $R$ represent the maximum blade velocity, angular blade velocity, and blade radius, respectively. The housing was made of clear plastic for flow visualization and the LDV experiment. The deck model was installed on a test stand and powered by a $5 \mathrm{hp} \mathrm{AC}$ motor (230 volts, $3450 \mathrm{rpm}$ ). The rotational speed of the blade was set at $2700 \mathrm{rpm}$ by a belt-pulley system. The height between
TABLE 1: Dimensions of tested deck and blade.

\begin{tabular}{clcc}
\hline Symbol & Dimension & Symbol & Dimension \\
\hline$D_{d}$ & $0.6 \mathrm{~m}$ & $L_{b}$ & $0.58 \mathrm{~m}$ \\
$L_{d}$ & $1.2 \mathrm{~m}$ & $V_{\max }$ & $82 \mathrm{~m} / \mathrm{s}$ \\
$H_{1}$ & $0.11 \mathrm{~m}$ & $\omega$ & $2700 \mathrm{rpm}$ \\
$Z$ & $0.08 \mathrm{~m}$ & $R$ & $0.29 \mathrm{~m}$ \\
\hline
\end{tabular}

the test stand and the bottom of the mower deck is adjustable from $0.025 \mathrm{~m}$ to $0.10 \mathrm{~m}$. The running belt guard was manufactured out of a $0.64 \mathrm{~cm}$ wood plate and a flexible steel plate to increase safety during the high-speed experiment. We attached the artificial grass mat to the wood plate $(0.8 \mathrm{~m} \times$ $1.4 \mathrm{~m}$ ) installed under the mower deck to simulate the working condition of a lawn mower in a field-test case. The LDV system was also installed to a movable traversing system to provide variable positioning, horizontally and vertically. The crank design improved adjustments in both $x$ and $y$ directions of the horizontal plane. The traversing system was fitted with two units, for vertical and horizontal adjustments. Three particle generators were installed to the test table to supply seeding for the LDV test.

A grass-feeding system was designed and constructed in the laboratory for experimental observations of cutting performance with a high-speed video camera. The grass-feeding system was designed to utilize a freestanding conveyor belt along with several sets of portable rollers. The speed of the main conveyor belt system can be adjustable via an electronic variable-speed digital motor controller, from $0 \mathrm{~m} / \mathrm{s}$ to $15 \mathrm{~m} / \mathrm{s}$.

\subsection{LDV system}

LDV is a well-established technique used in fluid flow research as a noninvasive method for obtaining velocity and turbulence information in a variety of applications including separated flows, liquid flows, high turbulence intensity flows, high-temperature flows, variable property flows (nonisothermal), rotating machinery, combustion, and very low velocity flows.

A 1980 TSI model LDV system was used to measure the velocities inside the housing. The LDV system consists of several pieces of equipment, including a laser source, optic system (beam splitter, focusing lens, collecting lens, Bragg cell, and photomultiplier tube), signal processor, and a data processor. The LDV has several optic system modes including reference-beam mode, dual-beam mode, one-beam mode, and fringe mode. The laser passes through the transmitting optics and the light beams intersect at a point creating a probe volume through which the seeding particle passes inside the mower housing. The scattered, two Doppler-shifted light signals that pass through the receiving optics are heterodyned in the photomultiplier. The different frequencies are sent to the data processor, which validates the signal and sends the processed data to a compatible data collection device.

The LDV system used in this experiment has one component, and a dual-beam mode system, powered by a $30 \mathrm{~mW}$ maximum output He-Ne ion laser. There are three types of 
scattered light collection; back scatter, forward scatter, and off-axis. The forward scatter method was chosen in this study to increase intensity.

\subsection{Seeding}

In most airflows, naturally present particles that can generate good signals are not sufficient in number. LDV measures the velocity of particles traversing the measured volume, but not the air molecules, so it is necessary to seed the flow field. Particles in the test room with a diameter greater than 0.5 microns have a number density (number/c.c.) typically less than 1 . This means that the probability of having a particle in the LDV measuring volume (e.g., 100 microns $\times 1000 \mathrm{mi}-$ crons) is very small. Hence, in most of the airflows, there is a need to seed the flow with appropriately sized particles. The optimum seed particles are small enough to follow the flow and large enough to generate a sufficient amount of scattered light. In general, the use of a water-glycerine mixture, or of oils (vegetable oils, mineral oils, and other liquids), is common to seed gas flows. In some cases, solid particles such as polystyrene latex (PSL), silicon beads, and kaoline have been used for seeding gas flows. Salt and sugar have also been used as seeds by atomizing the solutions and then drying the droplets. In these cases, the seed-particle size is controlled by adjusting the concentration of the solutions. Small particles for forward scatter applications have been generated in this fashion.

The frequency response is a function of the particle diameter and density. In general, a particle with a small, aerodynamic diameter would be a good choice as the seed for high-speed flows. As the diameter gets smaller, signal-tonoise ratio (SNR) could be maximized by reducing the measuring volume and increasing the laser power. Small solid particles such as PSL and titanium dioxide $\left(\mathrm{TiO}_{2}\right)$ have been used to seed high-speed flows. A solution of solid particles in an evaporating medium is atomized to control the seedparticle size. Droplets of atomized liquids such as silicone oils and Dow Corning 704 have been used as seed particles. One problem with using the laser velocimetry in flows containing regions of high vorticity is that the seeding particles will not precisely follow the trajectories of fluid elements because they tend to spin out from the measuring section due to the centrifugal effects. Another problem is that the deck model has clearance between the housing and the test table. Therefore, the particles used should be harmless to humans. Tests were performed by supplying atomized water droplets from an ultrasonic nozzle. Water droplets are continuously supplied from three nozzles installed on the test table.

\subsection{Grass-feeding system}

The central components of the grass-feeding system are the freestanding conveyor belt driven by a three-horsepower electric motor and several sets of portable rollers. The running motor with $1750 \mathrm{rpm}, 230 \mathrm{VAC}$, and $12.5 \mathrm{~A}$ input is used for controlling the speed of the conveyor belt. The system is capable of cutting a $1.37 \mathrm{~m}$ wide by $13.5 \mathrm{~m}$ long section of sod in approximately seven seconds. This system is an invaluable

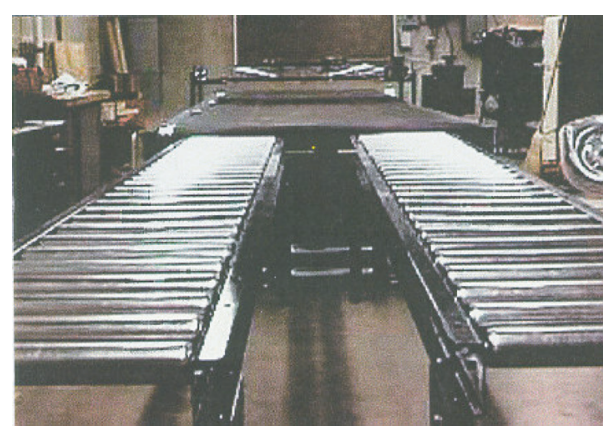

FIgURE 3: Front view of grass-feeding system.

tool for the validation of a theoretical model being developed.

In addition to the conveyor, several sets of portable rollers were used to bring the total length of the system to approximately $16.5 \mathrm{~m}$. This allows for the sod to be laid out on the deck before any experiments are performed. Each portable roller is $0.46 \mathrm{~m}$ wide and $3.0 \mathrm{~m}$ long; hence two rollers must be used in a parallel arrangement. There are a total of eight portable rollers, extending the entire grass-feeding system to a total length of $16.5 \mathrm{~m}$. A front view of the grass-feeding system is shown in Figure 3.

Several components had to be fabricated to create the grass-feeding system. The conveyor deck is powered by an electrical motor, in conjunction with an electrical control box, which was provided with the conveyor unit. A Rockwell Automation SP 500 AC variable speed controller was selected based on the motor size ratings and the minimum speed required. This system can provide more power than needed to convey the desired amount of sod at the predetermined speed. The maximum cutting speed of an actual mower is $2.22 \mathrm{~m} / \mathrm{s}$ and the average cutting speed is $1.34 \mathrm{~m} / \mathrm{s}$. The grassfeeding speed can be controlled by the motor's speed controller. When the grass-feeding speed is determined, the rpm can be set by the equation

$$
\mathrm{rpm} \text { of motor }=327.4 \times \text { grass-feeding speed }(\mathrm{km} / \mathrm{h}) .
$$

In addition, a mower deck mounting platform with adjustable height was attached to the frame of the conveyor system at $1.2 \mathrm{~m}$ from the end of the grass-feeding system. The mower deck support assembly, which uses a three-sided angle iron frame, firmly holds the mower deck above the belt of the conveyor system. The front side of the mower deck support is open so that the support frames would not affect the grass being fed into the blades. The horizontal supports were constructed so the positions of the support bolts could be simultaneously adjusted to the desired height. The operational motor of the lawn mower is also installed over the grass-feeding system with the vertical adjustable support frames.

\subsection{High-speed video camera}

The flow patterns were observed using a high-speed video camera. High-speed videotaping offers valuable insight into 


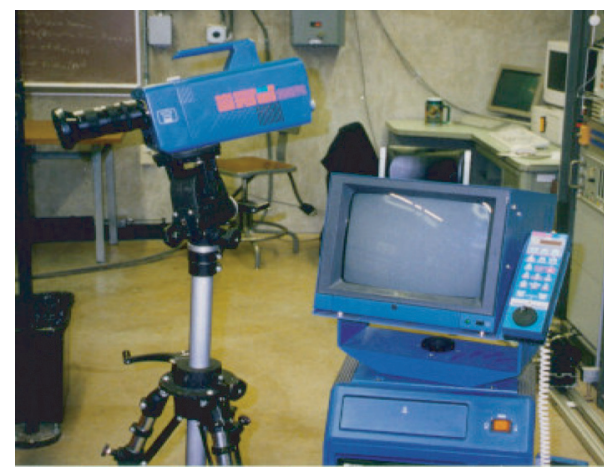

FIgURE 4: View of the high-speed video camera system.

the global flow patterns within the mower deck and is useful when comparing the performance of different blades. For these experiments, footage was recorded at several different angles. The NAC color high-speed video HSV-1000 FPS camera $\mathrm{V}-054$ was used. It has the ability to record up to $14 \mathrm{~min}$ utes of high-speed motion, at 1000 frames per second, on a standard color Super-VHS cassette. For added versatility, the system is easily switched to monochrome operation for those times when a black and white image is more appropriate. The complete system consists of a videotape recorder (VTR) and a video monitor, mounted on an integral card, and the HSV1000 color camera. An easy-to-use, handheld keypad controls all record and playback functions. The camera also has record and playback controls on its rear panel. The recording speed is adjustable at either 500 or 1000 frames per second with variable shutter speeds to help capture a sharper picture. The system has switchable recording formats for either Super-VHS or VHS, with a resolution of $350+$ horizontal TV lines. The monitor has a $750+$ horizontal line resolution and the camera has a $400+$ line video resolution. After the taping session is over, the footage can be played back at any speed or slowed to a still position through a rotary control for a frame-by-frame analysis. Both blade models were taped and compared at the same running conditions. Videotaping was performed from several different angles of view throughout the deck. The coalescence of small pieces of paper, the confetti test, was also observed by videotaping the flow motion. Figure 4 shows the high-speed video camera system used for this study.

\subsection{Sound level meter}

Noise levels were measured with a Bruel \& Kjaer precision sound level meter-type-2203. The sound level meter was calibrated by using a sound level calibrator-type- 4230 before the measurement. This calibrates the meter at $1000 \mathrm{~Hz}( \pm 2 \%)$, making it operate independently of the weighting networks. After calibration, it is possible to perform sound level measurements to an accuracy of $\pm 0.3 \mathrm{~dB}$.

The influence of static pressure is very small, thus the calibration signal is virtually independent of barometric pressure, or altitude, for ordinary use. The calibration may also be regarded to be independent of temperature for most applications.

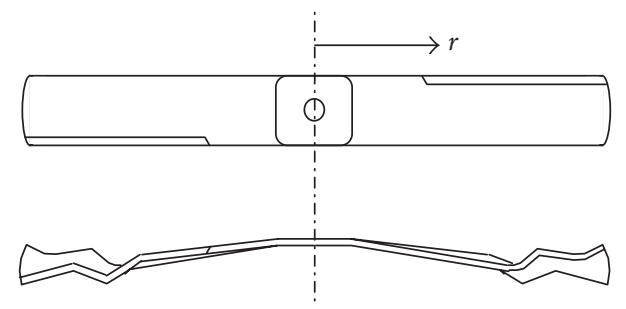

FIGURE 5: Schematic diagram of tested blade.

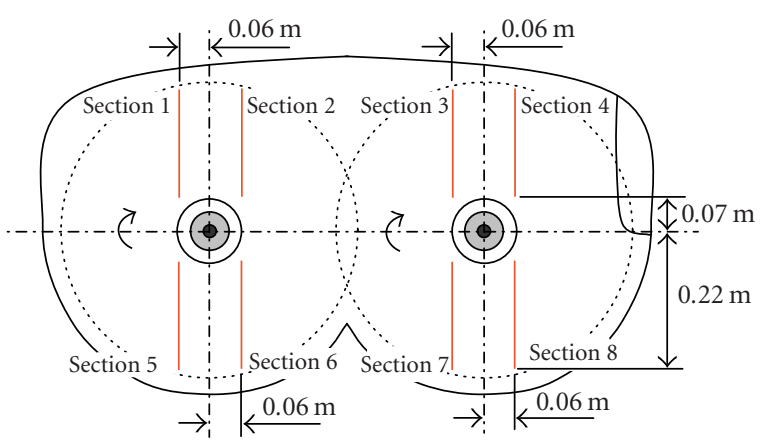

FIGURE 6: Selected sections for LDV measurements.

\section{EXPERIMENTAL PROCEDURE}

Figure 5 shows the schematic diagram of the tested blade model. There is a deep attack angle at the tip of the blade. Eight cross-sections shown in Figure 6 were chosen to collect data. Axial velocities were also measured at two different axial height positions in relation to the tip of the blade. Two different heights between the mower deck and the test table, $H_{2} / H_{1}=0.346$ and 0.577 , were also tested.

The velocity data obtained from the LDV system were processed in the data acquisition system. This system will display a real-time probability distribution function (PDF) histogram of the particle velocities, and a statistical analysis of the sample taken, including the number of points taken, velocity mean, standard deviation, turbulence (\%), a skewness coefficient, and a flatness coefficient. The data can be stored on a computer disc and retrieved for viewing or printing.

Preliminary tests with the lawn mower were conducted to determine the proper settings for the data processor, which would be kept constant throughout most of the tests. For each set of test conditions, the test section was positioned to pass through the center of the probe volume and intersect the optical axis, within the plane of the intersecting laser beams. The real-time PDF was viewed while the mower was running to assure that the processor settings were appropriate. When it was determined that the mower, processor, and software were all functioning properly, and adjusted correctly, a sample of 6,000 data points was taken and stored. These data were later analyzed and displayed as a PDF histogram and a table of available statistics for each set of test conditions.

In summary, each measurement was taken at the horizontal test section inside the mower housing. All of the data for each sample are available in its PDF data file and displayed 
in the PDF histogram. The LDV graphs were produced using the average velocity in each sample.

The high-speed videotaping was performed with several different running conditions for observing the flow pattern. Noise levels were measured with a sound level meter at several locations with the same testing conditions. Mower deck Models I and II were tested under the same running conditions. The measured values were averaged and recorded to compare the two decks.

\subsection{LDV measurement}

The results of the LDV tests provide a means of observing the velocity profiles for both the tangential and axial airflow directions at certain locations in the mower deck. From the velocity profiles, general observations can be made for airflow patterns. From these observations, explanations for the flow patterns can be assumed and validated with the high-speed camera tests or further LDV testing. Favorable airflow patterns can be replicated and improved with further LDV testing, while unfavorable airflow patterns are eliminated. The remainder of this section describes the velocity profiles determined by the LDV tests and includes possible reasons for both favorable and unfavorable patterns.

Several azimuth sections were selected for velocity measurements. For each section, 15 points at $1 \mathrm{~cm}$ increments along the blade, from the tip to the center of the rotation, were measured. Both the tangential and axial velocities were measured at every point. For the experiments using the LDV system, several methods were employed. Since the LDV measures the particles that move along with the airflow, different particles were considered for use in this experiment. Atomized water droplet particles were mainly used for seeding during the LDV test.

For the first test, the deck height (the clearance between mower deck and test table) was set at $0.064 \mathrm{~m}\left(H_{2} / H_{1}=\right.$ 0.577). This is the average height of an actual mower deck.

At a fixed mower height of $0.064 \mathrm{~m}$, the LDV system can be moved to different section height locations. The reference section, located at the tip of the blade (zero reference section, $z / Z=1$, where $z$ is the distance from blade surface on axial direction) was increased to measure different layers of flow velocities. The section heights from the zero reference section are set as $0.025 \mathrm{~m}(z / Z=0.313)$ and $0.035 \mathrm{~m}(z / Z=0.438)$. All measurements were also performed at the deck height of $0.038 \mathrm{~m}\left(H_{2} / H_{1}=0.346\right)$ with the same procedures.

\subsection{High-speed video camera test}

Three different tests were performed with a high-speed video camera. The first videotaping was performed by feeding small paper pieces into the mower deck, known as the confetti test. The camera was placed at several different positions on the deck to record this test. The particle flow of the paper clippings was observed, traveling around the path inside the deck and then being discharged through the outlet of the mower.

In addition, $0.04 \mathrm{~m}$ strings were attached on the inner wall of the deck during high-speed videotaping. The purpose

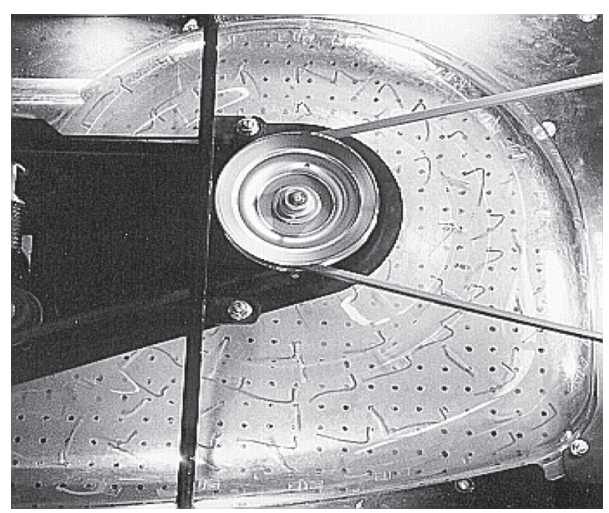

Figure 7: High-speed video test (tuft method).

of this tuft method was to observe the unpredictable flow patterns inside the deck housing. Suction, blowing, and turbulence are the main flow characteristics that need to be controlled for designing a mower deck with good performance. Figure 7 shows a partial view of the tuft method used in this experiment.

The third videotaping was performed with $1.2 \mathrm{~m} \times 1.2 \mathrm{~m}$ sections of actual grass on plywood. Four rollers were used with the conveyor belt grass-feeding system so that all sod pieces could be cut in sequence while rolling them in at the proper height to be accepted by the conveyor belt. A few different camera angles were tried for each run of this experiment.

\section{EXPERIMENTAL UNCERTAINTY}

It is assumed that the LDV system is measured on a real Doppler burst. The error in the counter measurement of time is $0.25 \%$ at $20 \mathrm{MHz}$. The digital data system uses 10 binary bits for $0.25 \%$ accuracy. The beam angle was measured by TSI and specified to $0.1 \%$. The total error of a Doppler burst measurement is therefore approximately $0.6 \%$, which is extremely small [1].

There is also the influence of velocity bias on the measurement. Velocity bias occurs because more high-velocity particles go through the measurement volume than lowvelocity particles. The data were screened at standard deviations, and only about $0.4 \%$ of the 6,000 data points were rejected in the experiments.

The source of error with the greatest potential for causing uncertainty is the measurement of noise, instead of Doppler bursts. The system and counter setup were checked so that no particle seeding corresponded to a zero data rate. It was also found useful to block the beam and make sure that the data rate went to zero. Generally, noise measurements made dropped considerably away from Doppler burst measurements. The LDV data assure that there is little problem with bad, noise-based measurements in the current data.

A $632.8 \mathrm{~nm}$ laser line was used for both the tangential and axial velocity components. These components were 
measured independently. Seed particles released from an ultrasonic nozzle ( $\sim 20 \mu \mathrm{m}$ diameter) were added to the fluid to provide acceptable data rates. Six thousand data points were taken at each position to determine the local mean velocity. Between 1,000 and 10,000, data points were averaged, and it was discovered that results were independent for sample sizes over 4000 data points.

Another error was introduced by the uncertainty of the traversing mechanism. The traversal resolution in the three directions was $\pm 0.2 \mu \mathrm{m}$ with a placement precision of $0.5 \mathrm{~mm} / \mathrm{m}$

\section{NUMERICAL MODEL}

The three-dimensional finite volume difference (FVD) method with QUICK [2] scheme for discretization of convection-diffusion terms and SIMPLEC [3] for pressure corrections was the numerical method used for this research. The turbulence model employed for the computations was the standard $k-\varepsilon$ with the wall-function model for the wallboundary conditions.

Two computational models were developed and combined with the computational code to better describe the aerodynamics of lawn mowers. First, several arbitrary radial cross-sections of two-dimensional blade shapes were selected for flow computations around the blade model. Each crosssection of the blade, drawn with CAD software, was modeled for flow computations. These blade cross-sections were transported into the CFD code and computed for flow behavior analyses. Second, a three-dimensional full deck model was developed with two corotating blades simultaneously in a single computational domain. We then compared and studied the experimental results with the three-dimensional CFD modeling results.

\subsection{Governing equations}

The governing equations needed to simulate a fluid flow field of the rotating blade at a steady-state condition are the conservation equations of mass and momentum, expressed in the vector forms shown as follows:

$$
\begin{gathered}
\nabla \cdot \rho \mathbf{v}=0 \\
(\mathbf{v} \cdot \nabla) \rho \mathbf{v}=-\nabla \cdot \pi+\rho \mathbf{g},
\end{gathered}
$$

where $\mathbf{v}$ is the air velocity vector, $\mathbf{g}$ is the gravitational acceleration vector, and total stress tensor $\pi$ is given by

$$
\pi=p \delta+\tau
$$

where $\delta$ is the unit tensor and $\tau$ is the shear stress. The above governing equations are valid for both laminar and turbulent flows. The following is the corresponding components in summation convection for repeated indices. The continuity equation is given by

$$
\frac{\partial\left(\rho U_{i}\right)}{\partial x_{i}}=0
$$

The momentum equation is given by

$$
\frac{\partial\left(\rho U_{i} U_{j}\right)}{\partial x_{j}}=-\frac{\partial P}{\partial x_{i}}+\rho g_{i}+\frac{\partial \tau_{i j}}{\partial x_{j}},
$$

where $U_{i}$ is the fluid velocity component in the $i$ th direction, $\tau_{i j}$ is the stress tensor, and $g_{i}$ is the gravitational acceleration in the ith direction.

Since the velocities of the flow in a lawn mower are small compared to the sound velocity, it can be assumed that the flow is incompressible. Thus, (4) and (5) reduce to

$$
\begin{gathered}
\frac{\partial U_{i}}{\partial x_{i}}=0 \\
\rho \frac{\partial}{\partial x_{j}}\left(U_{i} U_{j}\right)=-\frac{\partial P}{\partial x_{i}}+\rho g_{i}+\frac{\partial \tau_{i j}}{\partial x_{j}}
\end{gathered}
$$

where

$$
\tau_{i j}=\mu\left(\frac{\partial U_{i}}{\partial x_{j}}+\frac{\partial U_{j}}{\partial x_{i}}\right)-\rho \overline{u_{i}^{\prime} u_{j}^{\prime}} .
$$

In (7), the term $-\rho \overline{u_{i}^{\prime} u_{j}^{\prime}}$ is referred to as the Reynolds stresses.

For computations of turbulent flows, the standard $k-\varepsilon$ model has been widely used for many applications. This is partially because it is relatively simple and has been proven to provide engineering accuracy for a variety of turbulent flows, including shear flows and wall-bounded flows. In addition, the $k-\varepsilon$ model is semiempirical since its constants are taken from simple, steady, and high Reynolds number flow experiments.

The $k-\varepsilon$ turbulence model is an eddy-viscosity model. The Reynolds stresses are assumed to be proportional to the mean velocity gradients, with the constant proportionality being the turbulent viscosity $\mu_{t}$ assumed to be isotropic and to play the same role as the molecular viscosity $\mu$. At the wall boundaries, the wall functions are used near the wall region to estimate the effects of the wall on turbulent flows. These functions are empirical and are used in lieu of solving the entire turbulent boundary layer.

In each iteration, several steps are executed. At the first step, the $U_{i}$ momentum equations are each solved in turn using the guessed values for pressure in order to update the velocity field. Since the velocities obtained in the first step may not satisfy the mass conservation equation locally, a "Poisson-type" equation is derived from the continuity equation and the linearized momentum equations. This "pressure-correction" equation is then solved to obtain the necessary corrections to the pressure field. Corresponding adjustments to the velocity components are also made. The $k-\varepsilon$ equation is solved using the updated velocity to obtain the distribution of the effective viscosity for turbulent flow. Any auxiliary equations are solved using the previously updated values of the other variables. The fluid properties are also updated. Finally, a check is made to see if equation sets converge. These steps are continued until the sum of 


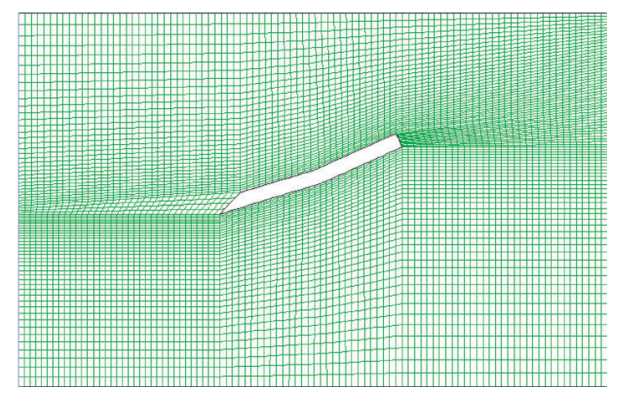

Figure 8: Final grid generation for two-dimensional blade crosssection $\mathrm{H}$.

the residuals in each equation, within each finite control volume, is less than a preset value $(0.01 \%)$, which means that the convergence results are obtained.

\subsection{Two-dimensional model}

One of the advantages of using a two-dimensional blade model is that the local flow behavior, and the effect of the blade geometry perimeters on the entire flow characteristics near the blade, can be observed more easily than with threedimensional models. Moreover, two-dimensional models are less complicated and require considerably less CPU time than three-dimensional approaches. Therefore, it was decided to start with a two-dimensional model to get some insight before moving on to three-dimensional models. With the blade spinning at $2700 \mathrm{rpm}$, the tip of the blade is moving at $82 \mathrm{~m} / \mathrm{s}$. In this manner the inlet velocity conditions were evaluated based on this rotational speed at each radial section:

$$
V_{\text {inlet }}(\mathrm{m} / \mathrm{s})=\frac{2 \pi \omega r}{60}
$$

where $r$ is selected point radius.

Before making the numerical computations, it is required to generate the correct geometry of the model and reasonable grids. The method and procedure for generating this geometry and the grids discussed below are valid for a twodimensional model.

Eight cross-sections of the blade were chosen to be calculated. The distances from each cross-section to the rotating axial line of the blade are $0.0922 \mathrm{~m}, 0.1082 \mathrm{~m}, 0.1342 \mathrm{~m}$, $0.1523 \mathrm{~m}, 0.1725 \mathrm{~m}, 0.2025 \mathrm{~m}, 0.2280 \mathrm{~m}$, and $0.2805 \mathrm{~m}$. A rectangular face with the dimension $0.205 \times 0.13 \mathrm{~m}$ was added around the cross-section view of the blade, with the blade located at the center.

In this study, a structured quadrilateral grid was used. Several different grid numbers were tested for velocity, static pressure, and turbulence, and it was observed that the variations of these variables became less than $0.1 \%$ for grids greater than 7000 . Therefore, 7546 total grid numbers, 98 (horizontal) $\times 77$ (vertical), were selected for the rest of the computations. The final grid for one of the two-dimensional blade models is shown in Figure 8. The upper and lower sides of the rectangle outside of the blade, and the geometry of the
TABLE 2: Input velocity for two-dimensional computation.

\begin{tabular}{ccc}
\hline Section & Radius $(\mathrm{m})$ & Input velocity $(\mathrm{m} / \mathrm{s})$ \\
\hline A & 0.0922 & 26.1 \\
B & 0.1082 & 30.6 \\
C & 0.1342 & 37.9 \\
D & 0.1523 & 43.1 \\
E & 0.1725 & 48.8 \\
F & 0.2025 & 57.3 \\
G & 0.2280 & 64.5 \\
H & 0.2805 & 79.3 \\
\hline
\end{tabular}

blade cross-section, were defined as walls. The velocity inlet was used for the inlet boundary condition, and the static pressure inlet was used for the outlet boundary condition.

The flow is assumed incompressible due to its low Mach number condition $(\mathrm{Ma}<0.2)$. This process of data input includes defining physical constants such as the density of air, set at $1.177 \mathrm{~kg} / \mathrm{m}^{3}$, and the viscosity of air at $1.846 \times 10^{-5} \mathrm{~N} \cdot \mathrm{s} / \mathrm{m}^{2}$. The input velocities obtained from the angular velocity for different cross-sections of the blade are shown in Table 2.

\subsection{Three-dimensional model}

In this phase of the study, an entire mower deck housing is used, simulating the real deck housing of an operational lawn mower. The solution domain consists of both upper and lower parts of the rotating blade in the deck hosing. The lower side of the computational domain is extended all the way to the ground.

The operational mechanism of this model is that the housing and the ground boundaries are kept stationary while the blades are rotating. The final rotating speed of the blades was $2700 \mathrm{rpm}$.

Unlike the case of a counter-rotating mower deck, the discharge-type mower is a corotating type, where the two blade chambers are not symmetric. For this reason, a threedimensional calculation should be done for the entire deck model. The fluid property parameters used are the same as those in the two-dimensional model. The lower side of the computational domain has been extended $0.064 \mathrm{~m}$ all the way to the ground. This is the average height of an actual mower deck. The constant grid distribution is used for all edges. Several different grid numbers were tested for the computation and it was observed that the variations of variables become less than $0.1 \%$ for grids greater than 95,000. Therefore, the total grid number of 110,160 , with 85 (azimuth $) \times 27$ (axial) $\times 48$ (radial) grid cells, was selected for the three-dimensional computation. The input velocities for the three-dimensional model are given from the angular velocity, with $2,700 \mathrm{rpm}=282.6 \mathrm{rad} / \mathrm{s}$ for each blade. Computations require approximately 20,000 iterations for the maximum relative residuals to drop below $0.01 \%$ on an SGI power challenge array at NCSA. The fully meshed threedimensional model is shown in Figure 9. 


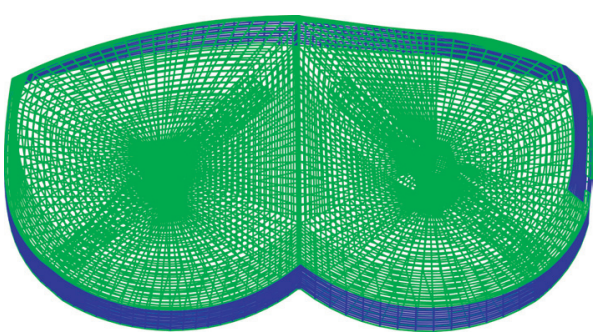

FIgURE 9: Final grid generation for three-dimensional full deck model.

TABle 3: Maximum tangential and axial velocity $(\mathrm{m} / \mathrm{s})\left(H_{2} / H_{1}=\right.$ $0.577)$.

\begin{tabular}{crccc}
\hline \multirow{2}{*}{ Section } & \multicolumn{2}{c}{ Tangential } & \multicolumn{2}{c}{ Axial } \\
& Model I & Model II & Model I & Model II \\
\hline 1 & 12.11 & 15.50 & 5.18 & 4.68 \\
2 & 16.39 & 17.79 & 7.16 & 4.93 \\
3 & 9.61 & 11.95 & 5.85 & 6.19 \\
4 & 13.49 & 14.13 & 6.39 & 7.04 \\
5 & 9.61 & 11.36 & 3.93 & 5.08 \\
6 & 13.81 & 14.89 & 6.25 & 5.47 \\
7 & 9.11 & 10.49 & 4.11 & 6.39 \\
8 & 11.73 & 11.25 & 6.19 & 5.17 \\
\hline
\end{tabular}

\section{RESULTS}

Velocity measurements were taken at several different radial and axial sections inside the deck housing. The maximum measured velocities are listed in Table 3 . The maximum tangential velocities usually occurred at $r / R=0.51 \sim 0.73$ from the center of the rotating shaft, and the maximum axial velocities usually occurred at $r / R=0.76 \sim 0.84$ from the center of the rotating shaft. This is because the velocities near the housing wall are reduced due to wall friction. The velocity distributions at each section are not the same due to the fact that air suction varies from location to location.

\subsection{Comparison between computations and experiments}

Figure 10 compares the velocities between computational and experimental results at several radial positions of section 1. In this figure, it is noted that both tangential (T) and axial velocities (A) agree well, except for the axial velocities at the position of $r / R=0.48$. The maximum velocities are higher in the computational results than in the experimental results for both the tangential and axial velocities because of simplifications of the computational model.

\subsection{Tangential velocity}

The measured results of the tangential velocity for the two different mower deck designs are shown in Figure 11. The total length of each test section was based on the physical limitations of the lenses of the LDV system with respect to the support deck. This figure shows that the two different

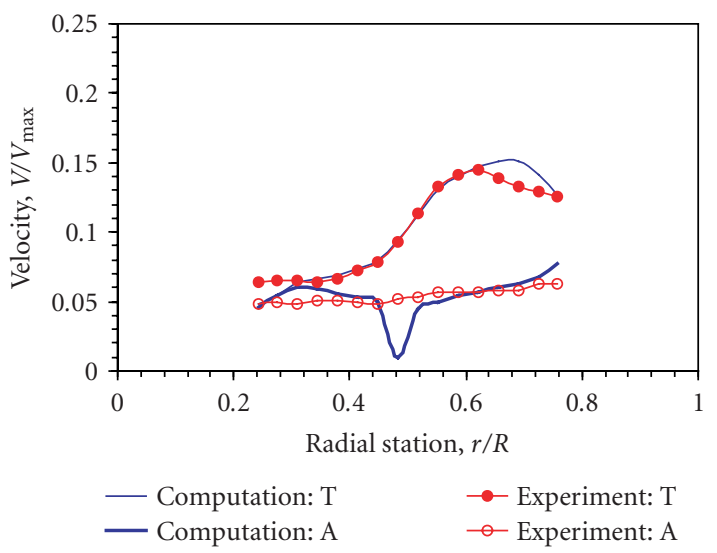

Figure 10: Comparison of computational and experimental results $(z / Z=0.313)$.

mower decks have a similar velocity pattern in each section. The measured maximum tangential velocity of Model I is $15.6 \mathrm{~m} / \mathrm{s}$ for $z / Z=0.313$, and $16.4 \mathrm{~m} / \mathrm{s}$ for $z / Z=0.438$ with $H_{2} / H_{1}=0.577$ within this distance range. Model II has a maximum tangential velocity of $16.9 \mathrm{~m} / \mathrm{s}$ for $z / Z=0.313$ and $17.8 \mathrm{~m} / \mathrm{s}$ for $z / Z=0.438$ with $H_{2} / H_{1}=0.577$.

From these observations, explanations for the flow patterns can be validated with the high-speed camera tests. Favorable airflow patterns can be replicated and improved with further LDV testing, while unfavorable airflow patterns can be eliminated. The remainder of this section describes the velocity profiles determined by the LDV tests and includes possible reasons for both favorable and unfavorable patterns.

The tangential velocity profiles have a tendency to increase from the center of the blades to the perimeter of the deck for both models. This trend is observed for all test sections except 5 and 6 . Sections 5 and 6 showed decreasing velocity from the center to the tip of the blade. This flow pattern may be a result of the inflow of air at this point of the deck, disturbing the patterns created by the rotating mower blades. This may also be a result of mower deck geometry. On average the magnitude of the tangential velocity was higher in the front (sections 1, 2, 3, and 4) of the deck than in the rear (sections $5,6,7$, and 8 ). This is a favorable characteristic since the majority of the grass is cut in the front and must be moved towards the discharge as quickly as possible to maintain high mower performance.

Interesting velocity profiles can be observed in section 2 (see Figure 11). The magnitude of the velocity is high at the center of the blades, then it decreases to a minimum of $r / R=0.3$ or 0.4 before beginning to increase again to a maximum of $r / R=0.6$ or 0.65 before it finally drops off again slightly near the perimeter of the deck. It is possible that the apparent increase from the minimum in the middle to the center of the blades is actually the result of the velocity of the airflow reversing directions at this point. The reversing airflow may be a result of the other blade near sections 7 and 8 causing a strong airflow closer to the center of the blades under sections $1,2,5$, and 6 . This reversing 


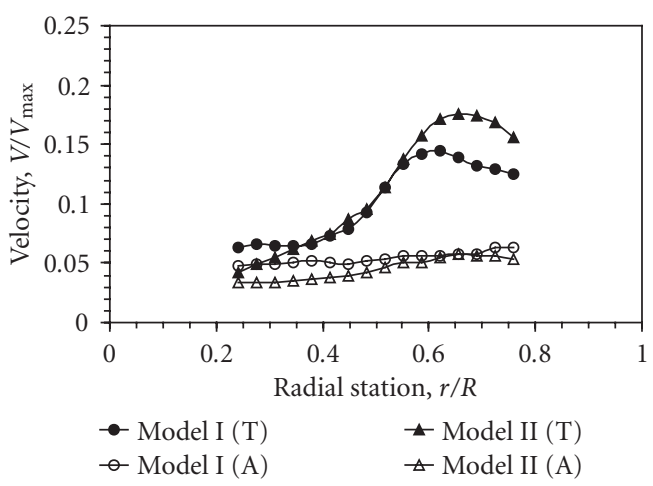

(a)

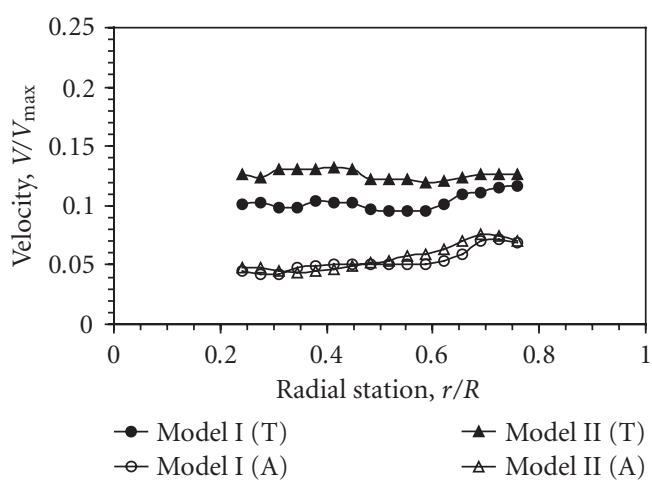

(c)

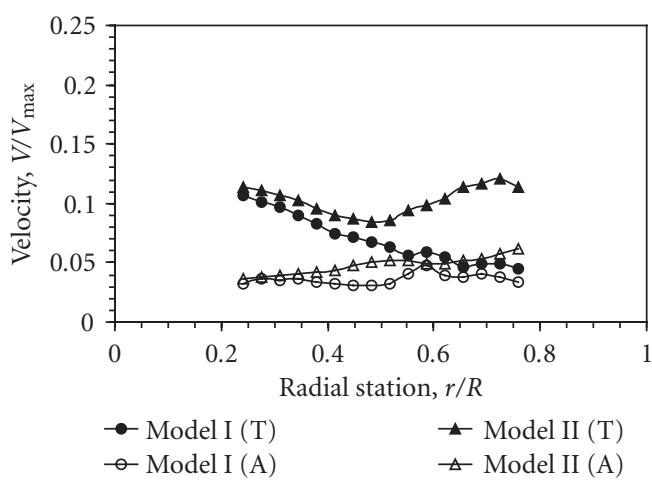

(e)

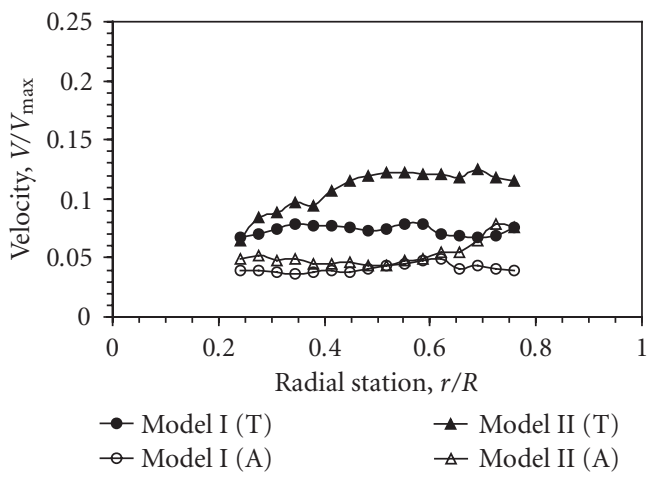

(g)

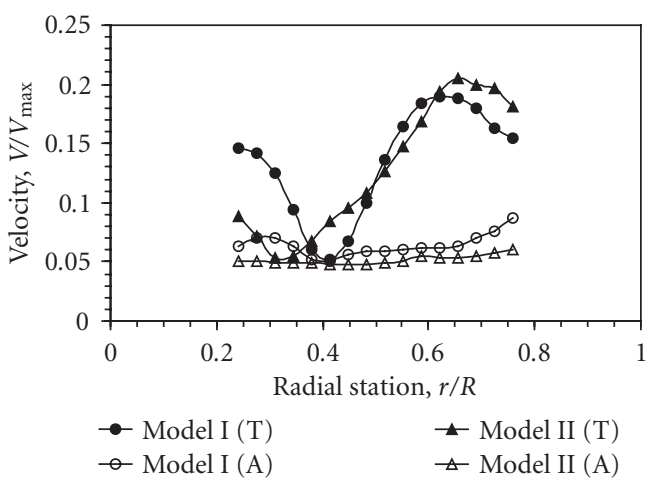

(b)

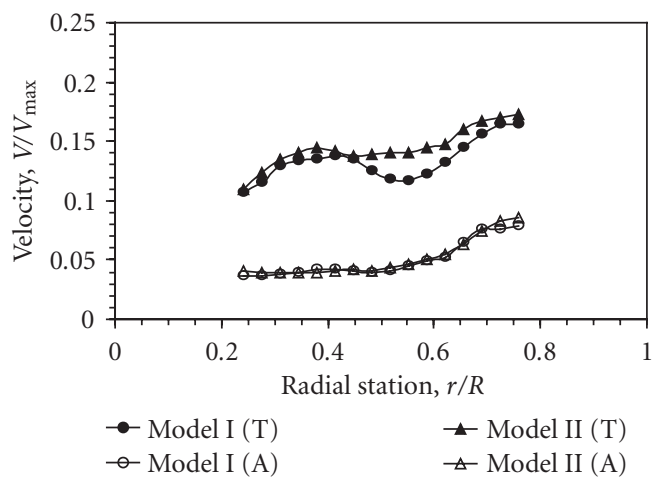

(d)

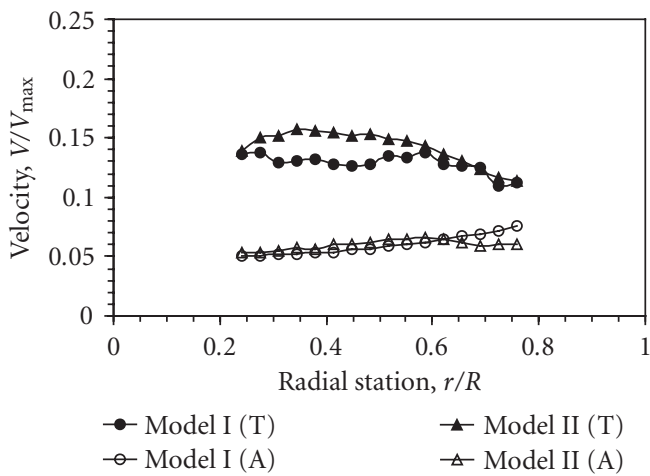

(f)

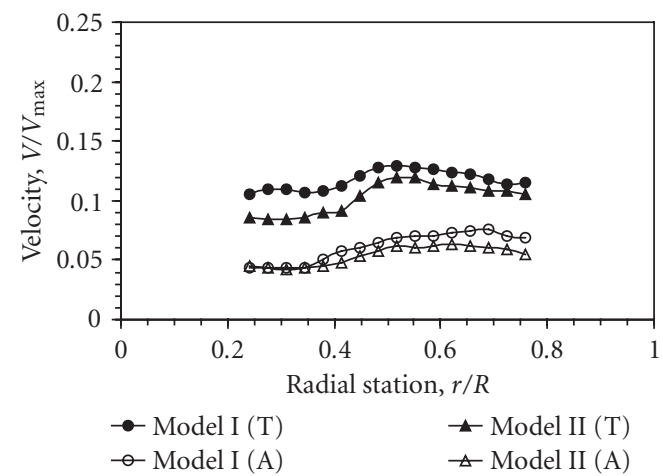

(h)

FIGURE 11: Tangential and axial velocity distributions (T: tangential, A: axial) $H_{2} / H_{1}=0.577, z / Z=0.313$. ((a) section 1, (b) section 2, (c) section 3, (d) section 4, (e) section 5, (f) section 6, (g) section 7, and (h) section 8.) 
flow mainly occurred around the center of section 2 . The minimum tangential velocity point is located closer to the center of the left blade $(r / R=0.3)$ on Model II while that point appeared at $r / R=0.4$ on Model I. The strong reversing flow was also observed during the tuft method with the high-speed videotaping at section 2 .

Table 3 shows the maximum tangential and axial velocity values near the blade with $H_{2} / H_{1}=0.577$.

\subsection{Axial velocity}

Figure 11 also shows the axial velocity profiles at the test point height of $0.025 \mathrm{~m}(z / Z=0.313)$ on the eight test sections for deck models. The maximum axial velocity of Model I is $7.16 \mathrm{~m} / \mathrm{s}$ for $z / Z=0.313$ and $6.03 \mathrm{~m} / \mathrm{s}$ for $z / Z=0.438$ with $H_{2} / H_{1}=0.577$ within this distance range. The maximum axial velocity of Model II is $7.04 \mathrm{~m} / \mathrm{s}$ for $z / Z=0.313$ and $5.95 \mathrm{~m} / \mathrm{s}$ for $z / Z=0.438$ with $H_{2} / H_{1}=0.577$. In all eight sections, the velocity increases from the center of the blades to the perimeter of the mower deck. This trend is beneficial in that the higher upward velocities occur near the perimeter causing the grass to lift before it is cut. This flow pattern improves the efficiency of the mower's mulching effect. Any grass that does not get cut by the first sweep of the blade has the potential to get cut in the following blade paths because they are stretched upward by the lift under the deck. The data also showed, on average, that the axial velocity in the front area of the deck was higher than the velocity in the back area in both models. This is also a beneficial velocity characteristic since the majority of the grass gets cut in the front of the deck. It was observed that all sections, except sections 5,7 , and 8 , had magnitudes of average axial velocity that ranged from 5 to $7 \mathrm{~m} / \mathrm{s}$. Sections 5 and 7 had slightly lower average velocities, but they are also located at the back of the mower deck. It is believed that the majority of the air suction is brought in through the back of the deck, which disturbs the axial airflow in this area by reducing the axial velocity.

\subsection{Comparison between different deck heights $\left(\mathrm{H}_{2}\right)$}

Two different deck heights were tested in this experiment, the average deck height of actual lawn mowers, $0.064 \mathrm{~m}$ $\left(H_{2} / H_{1}=0.577\right)$, and the minimum height, $0.038 \mathrm{~m}$ $\left(H_{2} / H_{1}=0.346\right)$. The velocity measurement for all eight sections was also performed under the same operating conditions.

Figure 12 shows the velocity distributions of the tangential and axial velocities in section 5. Both the tangential (T) and axial velocities (A) with $H_{2} / H_{1}=0.346$ have faster values than the velocities with $H_{2} / H_{1}=0.577$ in section 5 .

In most sections, the tangential velocity increases as the height of the test section is raised from $0.025 \mathrm{~m}$ to $0.035 \mathrm{~m}$. The axial velocity of the tests at the height of $0.025 \mathrm{~m}$ showed average velocities slightly higher than the tests at $0.035 \mathrm{~m}$ for most sections.

\subsection{Comparison between different section heights $(z)$}

Two different test section heights were tested. Figure 13 shows the comparison of tangential and axial velocity

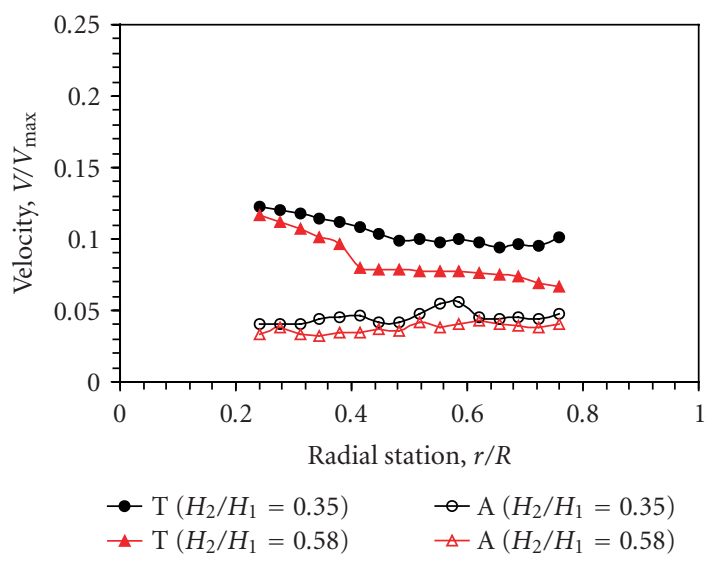

Figure 12: Comparison of different deck heights for section 5 $(z / Z=0.438)$.

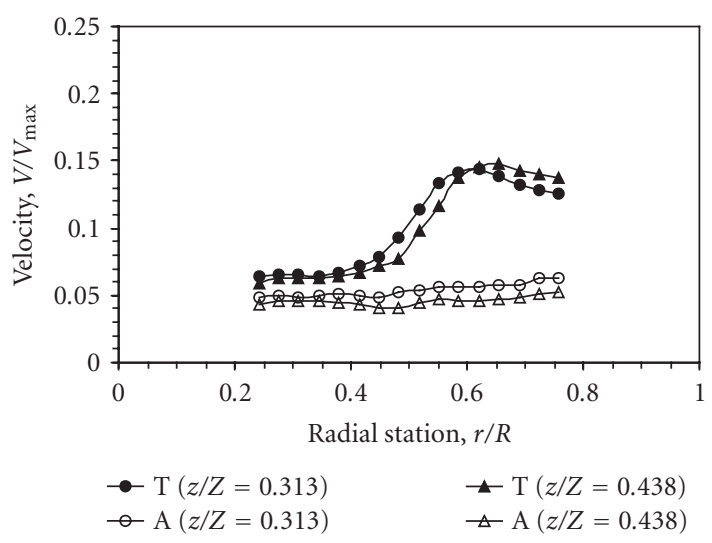

FIGURE 13: Comparison of different section heights for section 1 $\left(H_{2} / H_{1}=0.577\right)$.

distribution for the different test section heights of $0.025 \mathrm{~m}$ $(z / Z=0.313)$ and $0.035 \mathrm{~m}(z / Z=0.438)$ for Model I at section 1 . It was observed that the velocity profiles for blade heights of $0.025 \mathrm{~m}$ and $0.035 \mathrm{~m}$ showed similar characteristics.

\subsection{High-speed videotaping}

Two different housing models were tested under the same running conditions. For the first videotaping experiment, small confetti was supplied to observe the flow motion while the blades were rotating. Several interesting flow patterns were observed after examining the taped cutting sessions. There was even more evidence of the air being forced out from the front of the mower deck, which is an undesirable effect. Ideally the mower should suck the grass into the deck, but due to the way the blades rotate they force air out from the front of the deck on their cutting pass. And the tuft test indicates strings aligning with blade rotation direction except at the center area of the deck. High turbulence was also observed at the center of the deck. The tuft test in the left deck clearly indicates strings aligning against the rotation of 


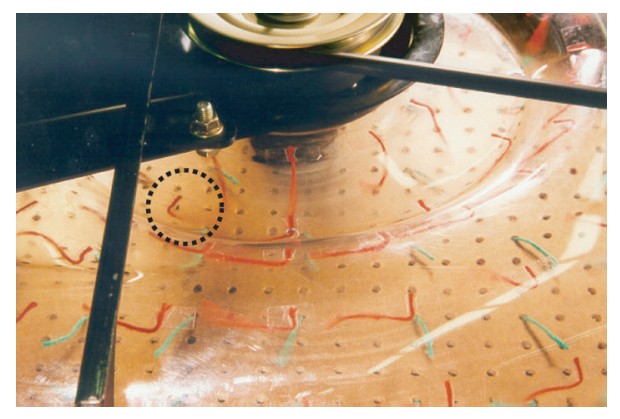

FIgUre 14: Tuft test view at section 2 for Model I.

TABLe 4: Noise test result (dB).

\begin{tabular}{ccc}
\hline Housing model & Without blade & With blade \\
\hline Model I & 79.4 & 86.5 \\
Model II & 79.5 & 86.0 \\
\hline
\end{tabular}

the blade in section 2 as shown in Figure 14. This is most likely due to the counter flow caused by the other blade in the right deck.

During one taping session the camera was placed on the side of the mower deck in order to show a profile shot of the deck. The tape showed that even though the grass was being blown away from the mower just before entering the deck, the blades of grass would immediately spring back up once inside the deck.

Camera footage also revealed that a large percentage of the grass is immediately cut and discharged upon first entering the deck. The steep angle on the outer edge of the blades is responsible for the quick discharge of the clippings. Any clippings that were not discharged on the first pass were drawn around in a circle by the blade on the discharge side of the deck. Very few clippings were visible on the rear portion of the drive side of the deck.

The tuft test showed that the flow inside of the deck was not steady. There was a visible pulsing of the airflow inside of the deck that occurred with every blade pass.

\subsection{Noise test}

The results of the noise test are listed in Table 4 . The sound level meter was used at various locations in the deck, including a section between the two blades, and these noise levels were averaged. The average noise levels were $79.5 \mathrm{~dB}$ without any blade installation, $86.5 \mathrm{~dB}$ with housing Model I, and $86.0 \mathrm{~dB}$ with housing Model II. Hence, each blade makes $6.5 \sim 7 \mathrm{~dB}$ increments of noise. The noise level created by Model II is about $0.6 \%$ lower than Model I, but noise differences are relatively small. The housing design of Model II causes both faster flow and less resistance in the housing.

\subsection{Two-dimensional computation results}

In two-dimensional models, high pressure occurs at the upper side of each blade cross-section and low pressure occurs

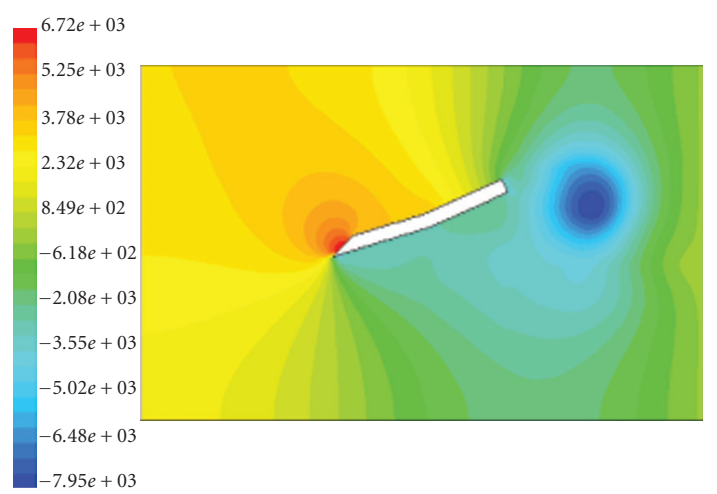

FIgURE 15: Static pressure contour at the blade section $\mathrm{H}$ (Pa, $r=$ $0.2805 \mathrm{~m})$.

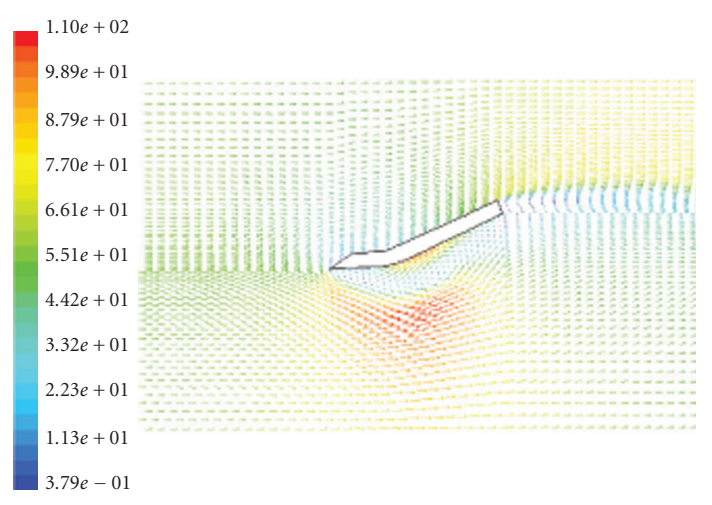

FIGURE 16: Velocity vectors at the blade section $\mathrm{F}(\mathrm{m} / \mathrm{s}, r=$ $0.2025 \mathrm{~m})$.

at the bottom of each blade. By inspecting these results, it can be seen that the highest pressure level occurs at the front edge of the blade. Figure 15 shows that the lowest pressure point is located behind the blade at section $\mathrm{H}(r=0.2805 \mathrm{~m})$.

Inspection of the velocity vector results, shows that the velocity vectors are relatively uniform in most of the flow field except at the bottom of the blade. There is a small vortex flow at the middle of the bottom surface caused by the flow separation at the sharp edge of the blade. At the trailing area of the blade, the velocity is nearly zero. It can be observed from Figure 16 that the larger vortex flow occurs at the bottom of the blade. This vortex creates a strong downward velocity at the bottom of the blade edge.

Two-dimensional turbulent results show that the tail region of the blade has the highest turbulent kinetic energy level since the large difference of velocity values between the upside and the trailing area of the blade cause unstable flow pattern.

\subsection{Three-dimensional computation results}

The contours of the absolute static pressure on three different horizontal planes are shown in Figure 17. The first plane (a) corresponds with the vertical location of $0.03 \mathrm{~m}$ above the blade, the second (b) is at the blade plane, and the third (c) 


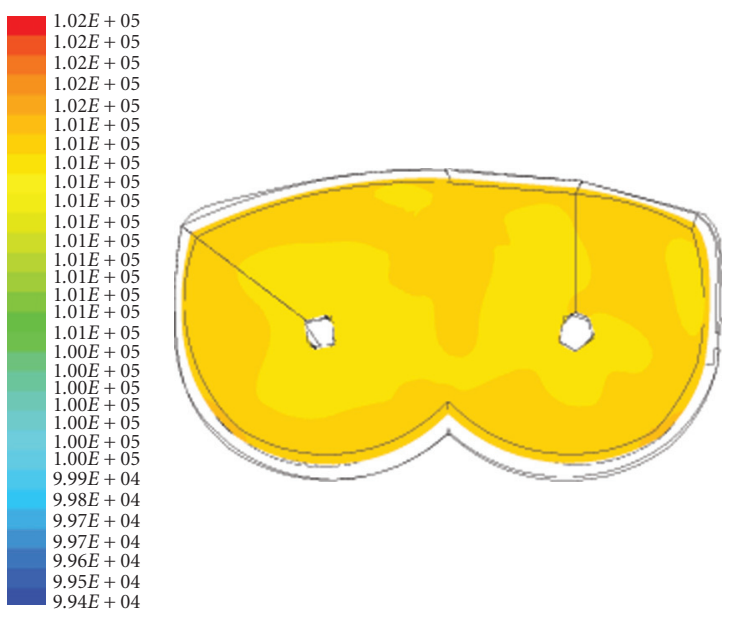

(a)
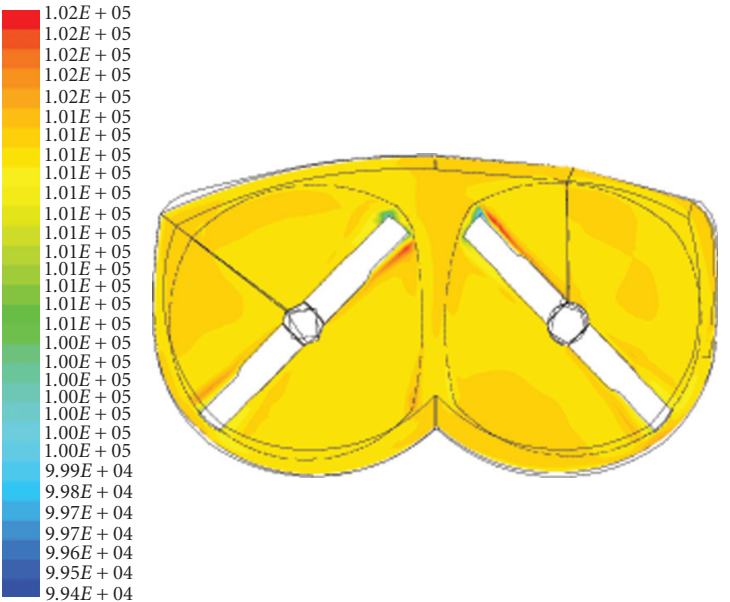

(b)
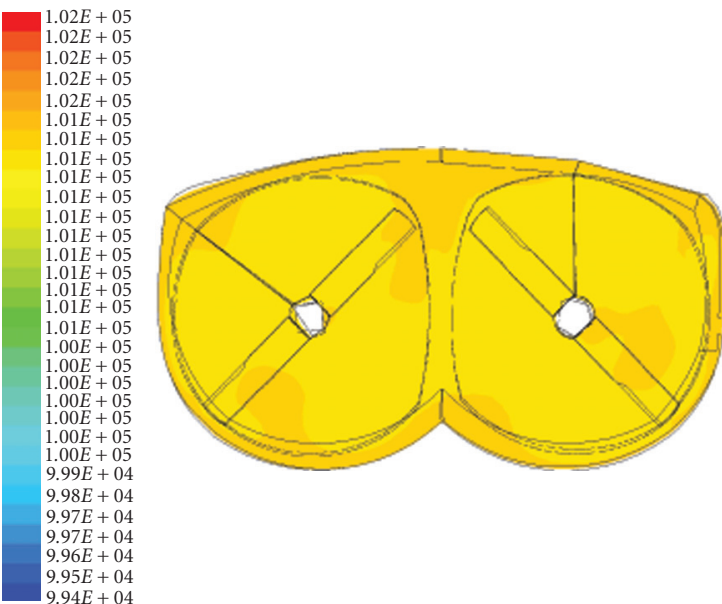

(c)

FIGURE 17: Static pressure contour at the horizontal planes (Pa): (a) plane above the blade, (b)plane through the blade, and (c) plane below the blade.

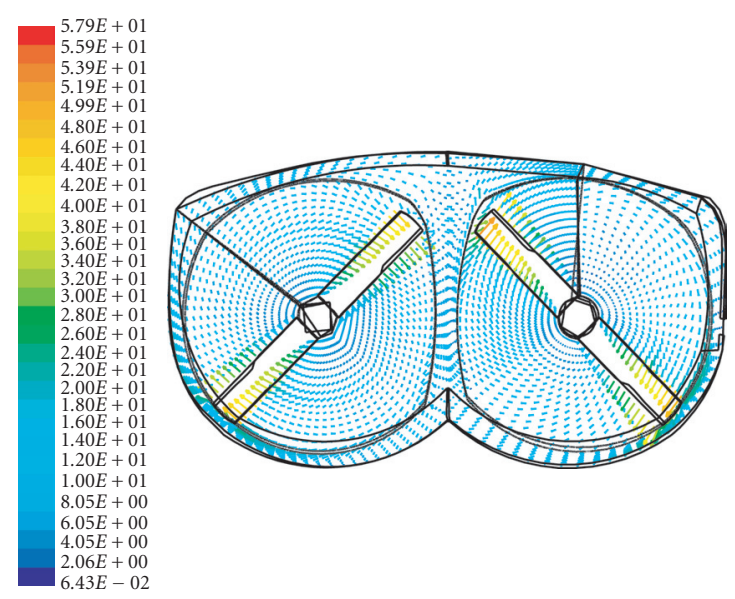

FIGURE 18: Velocity vectors at the horizontal plane through the blade $(\mathrm{m} / \mathrm{s})$.

is $0.03 \mathrm{~m}$ below the blade plane. The level of pressure above the blade plane is generally higher than the region under the blade plane. Figure 17 also shows that the highest pressure point appears at the front of the rotating blades and the lowest point occurs around the tip of the blades. Also it is noted that the pressure level is generally lower near the rotating centers, and the area around the discharge part has lower static pressure. However, the difference between the maximum and minimum values is relatively small $(3 \mathrm{kPa})$.

The total velocity vectors at the blade planes are shown in Figure 18. The velocity at the front region of the deck is faster than at the rear region. It also clearly shows the discharge direction of air at the discharge point. Several small swirling flows occur. This type of swirling flow was also observed with the high-speed camera test on the deck ceiling. In most of the housing, the air flows from left to right at the center region. The three-dimensional results show that small swirling also occurs at the region of the front side below the blade plane since two different airflows are crashing into each other. This phenomenon matches with the tuft test in which small swirling spots appeared. Another reason is the pressure difference caused by the discharge effect. It also shows that air suction occurs most in the area on the rear side of the deck. This was also confirmed in the experiments on the deck Models I and II. Inlet velocities around the rear side of the housing wall become higher when blades pass that region. This also shows that the air flows from right to left at the center region of the housing.

Figure 19 shows the velocity vectors for the radial plane at the left and right side. It shows velocity patterns occurring near the tip of the blade when blade is rotating.

The front-right side center and rear-left side center regions of the mower have the highest turbulence energy levels since the flows from two different directions crash into each other around this region. In the area around the tip of the blade the level of turbulent kinetic energy is higher than in the rest of the region. The turbulent results also show that turbulent energy levels in the right side of the housing are 


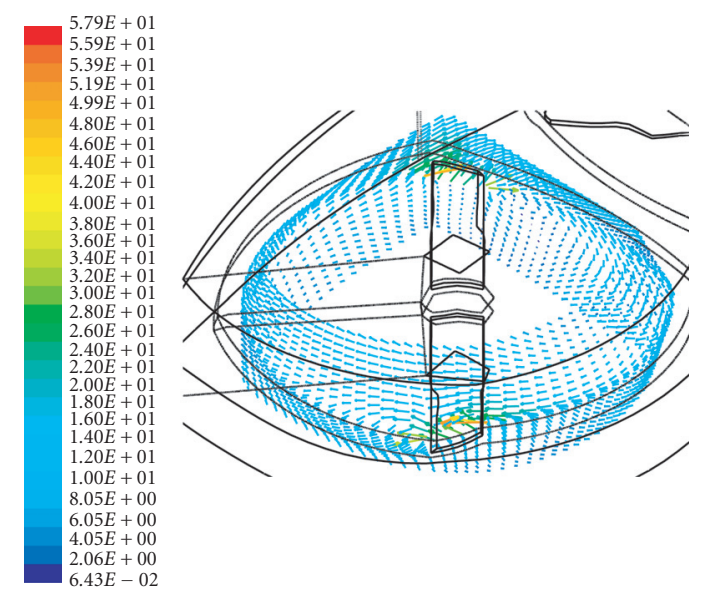

(a)

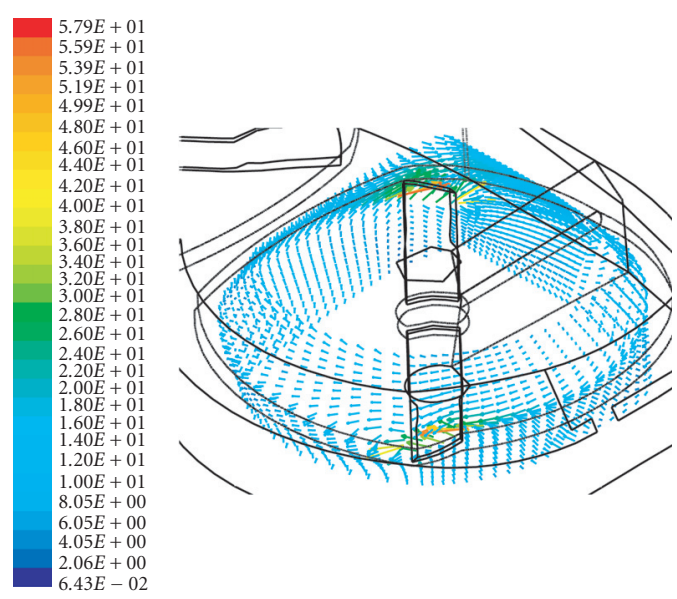

(b)

FIgURE 19: Velocity vectors at the radial planes $(\mathrm{m} / \mathrm{s})$ : (a) at the plane of left side (b) at the plane of right side.

higher than that in the left side of the housing because of the discharge area. However, the difference between the maximum and minimum values for the turbulent kinetic energy level is relatively small. This observation also corresponds to the noise test results.

\section{CONCLUSIONS}

Through this study, the experimental and computational results have provided a better understanding of the velocity patterns generated at each section inside the mower deck during operation. Hence, an optimum design of mower blade can be found in consideration of the relation between better performance and lower turbulent energy.

The computational calculations of the blades for a discharge-type mower deck clearly show the flow pattern and other flow characteristics around the blade cross-sections. These results can also be used for future blade modifications or new design developments.
The use of an LDV system and high-speed video, along with the use of CFD code, has given us an opportunity to verify computational flows with visual experimental results. The experimental results have provided a good picture of what the velocity patterns at each section inside the mower deck look like.

The LDV test results show velocity magnitudes throughout the mower deck in both tangential and axial directions. Some sections have been found to have lower velocities than total average velocity. The front inner section (section 2) of the mower deck has more dynamic flow results than other sections. This is due to the interacting actions of the flows approaching from each deck compartment. The two corotating blades cause flow patterns at this point. This phenomenon was also observed with the high-speed videotaping test. The front inner section (section 3) of the mower deck appears to have more evenly distributed velocities.

Mower deck Model I was redesigned to improve the flow performance inside the housing. The performance results were compared between Model I and II, and it was found that the redesign of the deck shape can improve the flow performance.

The front sections (sections 1, 2, 3, and 4) have relatively faster tangential and axial velocities than the rear sections (sections 5, 6, 7, and 8). The rear inner sections near the discharge area (sections 7 and 8 ) show a very unstable velocity pattern caused by the most complex airflow. To minimize the instability of the velocity, several modifications of housing and blade design are required in future studies.

Computational model calculations agree well with the experimental results except at one point in section 1 . The difference of several axial velocities between computational and experimental result seems to occur by the simplification of the deck design for computation. This computational study of a lawn mower can provide a method of determining optimum values for critical design parameters before experimental validations are performed for many other complicated rotating machinery designs.

Observation with the high-speed videotaping creates a good opportunity for visual verification and comparison with the LDV test. This information can be used in future designs of both mower decks and other blades to achieve more desirable flow patterns.

\section{ACKNOWLEDGMENT}

Computations were performed using power challenge array at NCSA (National Center for Supercomputing Applications) under NSF Grant CTS970045N.

\section{REFERENCES}

[1] TSI Co., LDV Instruction Manual.

[2] B. P. Leonard, "Simple high-accuracy resolution program for convective modelling of discontinuities," International Journal of Numerical Method for Fluids, vol. 8, pp. 1291-1318, 1988.

[3] J. P. Van Doormaal and G. D. Raithby, "Enhancements of the SIMPLE method for predicting incompressible fluid flows," Numerical Heat Transfer, vol. 7, pp. 147-163, 1984. 

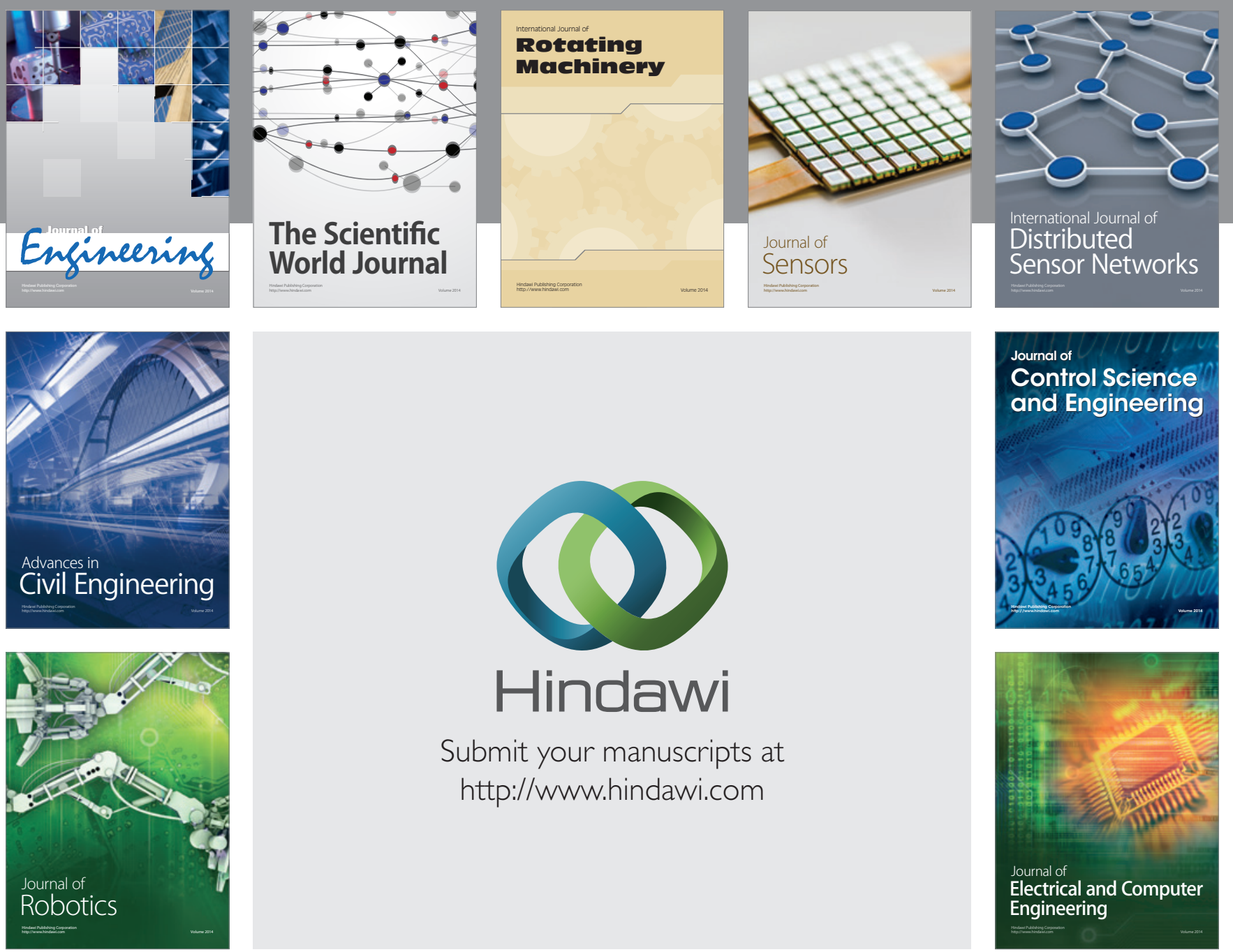

Submit your manuscripts at

http://www.hindawi.com
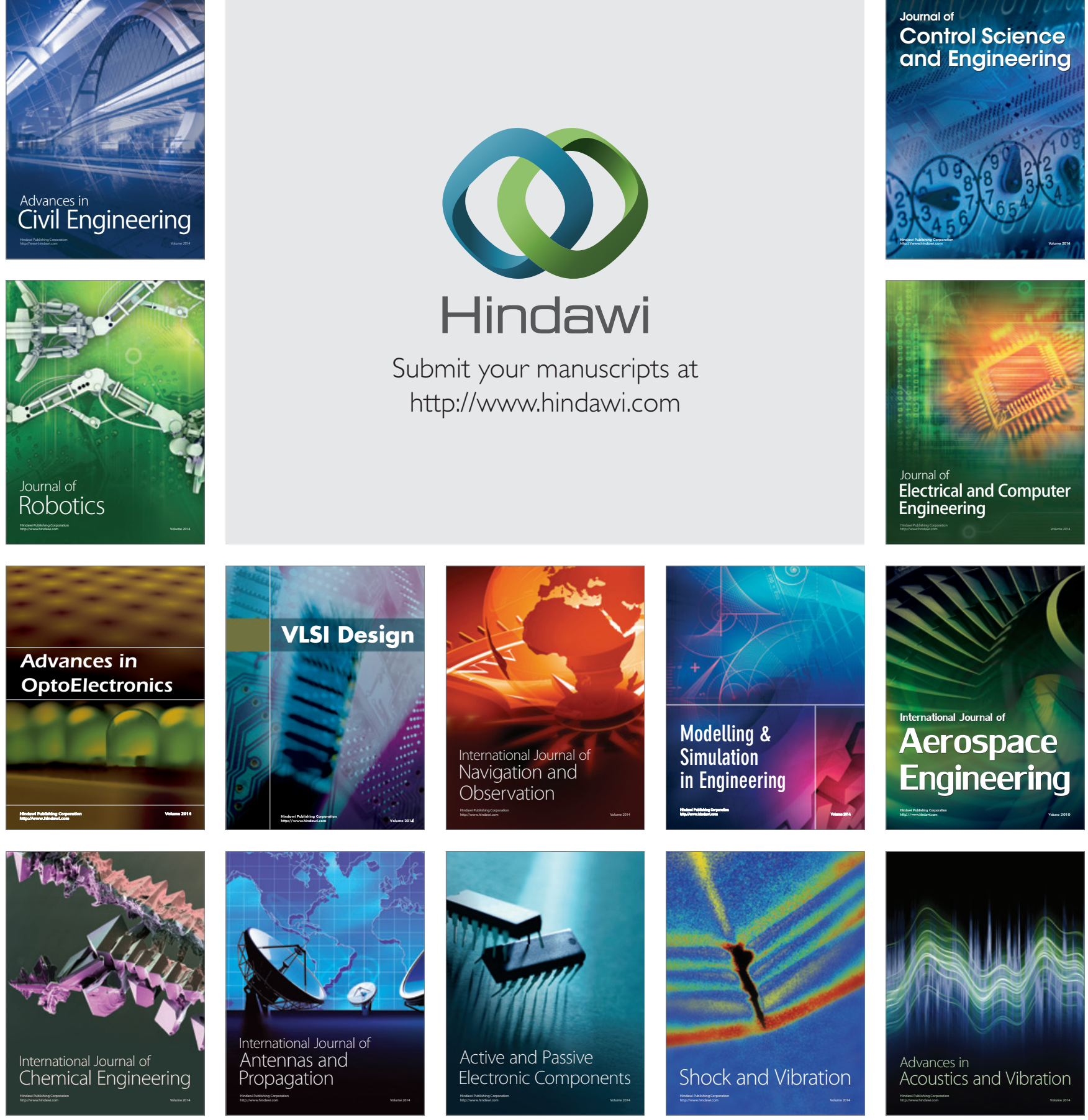